\title{
Analysis of turbulence and extreme current velocity values in a tidal channel
}

\author{
Patxi Garcia Novo ${ }^{1}\left[\right.$. Yusaku Kyozuka ${ }^{2}$
}

Received: 11 May 2018 / Accepted: 1 October 2018 / Published online: 9 November 2018

(c) The Author(s) 2018

\begin{abstract}
Tidal stream energy has emerged as one of the most promising alternative energy sources to the use of fossil fuels. Nevertheless, there are some crucial issues that must be overcome. One of these key aspects is the response of tidal stream energy converters to the extreme velocities related to high-frequency velocity perturbations from the mean current speed. In this study, the dependence of this velocity fluctuation on the turbulence conditions of the flow is analysed based on the data measured during 1 week by two Acoustic Doppler velocimeters in two tidal channels in the Goto Islands, Japan. At one of the channels, where maximum 3-min averaged measured velocity is $1.7 \mathrm{~m} / \mathrm{s}$, extreme values over $3 \mathrm{~m} / \mathrm{s}$ were observed. Turbulence intensity ranges between 10 and $35 \%$, with a clear contrast between flood and ebb conditions at one of the measuring points. Peak velocity, in terms of a peak-to-averaged ratio, and turbulence intensity calculated for 3-min periods were compared, obtaining linear trends with similar slopes for both measuring points and under different flow conditions. Since turbulence conditions can be simulated by numerical modelling, the presented correlation opens the door to prediction of extreme velocities, reducing the need for in situ measurements.
\end{abstract}

Keywords Tidal current $\cdot$ Turbulence $\cdot$ ADV $\cdot$ Extreme velocity

\section{Introduction}

In recent years, tidal stream energy has emerged as one of the potential solutions to the world energy crisis and as a countermeasure to global warming. Though it is still at a stage prior to industrial commercialization, pilot plants in the Bay of Fundy (Canada) [1] or the Orkney Islands (Scotland) [2], among others, are already operational. Recently, the Goto Islands of Nagasaki Prefecture, in southwestern

Electronic supplementary material The online version of this article (https://doi.org/10.1007/s00773-018-0601-z) contains supplementary material, which is available to authorised users.

Patxi Garcia Novo

patxi@galaxy.ocn.ne.jp

Yusaku Kyozuka

kyozuka@nagasaki-u.ac.jp

1 Nagasaki Marine Industry Cluster Promotion Association, 1-43 Dejima-machi, Nagasaki 850-0862, Japan

2 Organization for Marine Science and Technology, Nagasaki University, 1-14 Bunkyo-Machi, Nagasaki 852-8521, Japan
Japan, have been chosen as a test site for tidal stream and other ocean energy devices [3].

Although some commercial size turbines have already been successfully tested at sites with high energy potential, durability is still a challenge. Some difficulties have been encountered because of exposure to marine corrosion [4] and biofouling [5, 6]. Another crucial topic is the strong impact on performance of turbulence, defined as the both temporal and spatial random changes of hydrodynamic characteristics in fluid flows. In recent years, various experimental and numerical simulation studies have addressed this matter by comparing the response of turbines to two or more different turbulent flows, which are defined by parameters such as turbulence intensity or integral time and length scales. These studies showed that turbulence-related parameters have direct effects on wake characteristics, power and thrust coefficients, and fatigue of the structure. Mycek et al. [7] observed a reduction of around $5-10 \%$ in the power and thrust coefficients of a 3-bladed turbine when increasing turbulence intensity from 3 to $15 \%$. Blackmore et al. [8], comparing three different flows (turbulence intensity $0 \%$, $5.6 \%$, and $11.7 \%$ ), found that, with increasing turbulence intensity, velocity deficit downstream was reduced and the 
point of maximum velocity deficit was closer to the turbine. Larger integral length scales (length scale/turbine diameter $=0.25-0.55$ ) had similar effects on wake characteristics. These trends were corroborated for higher turbulence intensities (up to 25\%) in a later study [9], which also showed that higher length scales result in an increase power and thrust coefficients. In terms of loads, it has been observed that larger turbulence intensity values cause a slight reduction in mean flapwise and edgewise blade root bending moments, but increase their fluctuation, while longer length scales produce an increase in both mean value and fluctuations [9]. Turbulence effects on tidal current turbines have also been studied by numerical modelling. By this method, Pyakurel et al. [10] observed similar mean shaft power $(370 \mathrm{~kW}$ and $384 \mathrm{~kW})$ and mean axial loading (139 kN and $140 \mathrm{kN})$ for $5 \%$ and $20 \%$ turbulence intensity flows, respectively. Nevertheless, standard deviations for these variables were four times higher for the second flow.

Other authors have focused on characterising the turbulence conditions at the most promising areas for tidal current energy extraction to predict the behaviour of turbines at these locations. These field studies are based on the measurement of high-frequency velocity data [11-13]. The results obtained differ depending on the location. In the Sound of Islay [11], data was measured with an ADV (Acoustic Doppler Velocimeter) at $5 \mathrm{~m}$ over the seabed at a point where mean flow reaches $2.5 \mathrm{~m} / \mathrm{s}$. Length scale and streamwise turbulence intensity around $11-14 \mathrm{~m}$ and $12-13 \%$, respectively, were found, with a small variation between ebb and flood conditions. This difference between flow directions was also observed in Puget Sound (WA) [12]. Results presented in this study for one of the two measuring points show notably higher turbulence intensities $(>25 \%)$ in the ebb tide, which is likely to be related to the presence of a headland close to the measuring device installation point. Finally, in Kobe Strait (Japan) [13], ADCP data at $8 \mathrm{~m}$ from the bottom show similar streamwise turbulence intensity values for flood and ebb tide (0.17-0.15), whilst length scale is almost double for the flood direction (12.3-6.64 m). Thus, there seems to be a direct relation between the local geomorphologic conditions and the turbulence characteristics of a site.

Instantaneous extreme velocities generated by turbulence are of concern for tidal turbine design. Changes of $50 \mathrm{~cm} / \mathrm{s}$ within a minute have been observed in Puget Sound, against an average velocity of approx. $2 \mathrm{~m} / \mathrm{s}$ [14]. Under similar average velocity and time period conditions, extreme velocities close to $25 \%$ higher than the mean value were reported in the Sound of Islay [11]. In the Kobe Strait study [13], for a 5 -min period with an averaged velocity of $2 \mathrm{~m} / \mathrm{s}$, instantaneous values close to $3 \mathrm{~m} / \mathrm{s}$ were observed. These extreme velocities, which cannot be predicted by regional-scale numerical modelling [14], might lead to turbine damage, as happened in the Bay of Fundy in 2009. In this case, the rotor blades of a 1-MW OpenHydro turbine were destroyed by tidal flows that were 2.5 times stronger than expected [15]. Field work has been done to try to understand the nature of these extreme velocities at strong tidal current sites and its effect on converter devices. Based on 1 month of data measured in Puget Sound [16], Harding presented a velocity perturbation prediction method for a 50 -year period at the same point with a Peak-Over-Threshold method, also used for extreme wind velocity studies. However, the author states that "several years of data are required to perform the analysis to an acceptable level of confidence". In addition to this time constraint, to date, all the studies regarding turbulence-related velocity fluctuation involve the need for in situ measurement, with the financial and logistical constraints this brings.

In this context, the present study has two aims: first, the evaluation of turbulence conditions in terms of turbulence intensity and integral length scale, and their potential effect on converters at two points in the Goto Islands, a promising site for tidal stream energy exploitation. Due to the strong tides, the proximity to the coastline and the relatively shallow depths, turbulence is expected to play a key role in this area. Second, providing the basis for a new method able to predict turbulence-related peak velocities. As current ocean models are able to simulate and predict turbulence intensity [from turbulent kinetic energy model results by $\left.\mathrm{TKE}=\frac{3}{2}(\mathrm{TI} \times \bar{V})^{2}\right][17]$ and mean velocity [18-20], this new method proposes a relation between these two parameters and extreme tidal stream velocities, which will enable the estimation of the latter by numerical modelling and contribute to reducing the costs of measurement and overconservative design.

\section{Field sites}

The Goto Islands form an isolated archipelago located in the East China Sea, Southwestern Japan (see Fig. 1). Part of Nagasaki Prefecture, the closest point of the archipelago is located around $100 \mathrm{~km}$ from Nagasaki Port. It consists of five main islands (from west to east, Fukue, Hisaka, Naru, Wakamatsu, and Nakadori), forming four main channels (from west to east, Tanoura, Naru, Takigahara, and Wakamatsu). The strong currents generated by the large volume of water flowing through these channels from the Pacific Ocean to the Japan Sea in flood tides and vice versa in ebb tides make of this area a suitable location for tidal stream energy exploitation. The maximum tidal range is slightly lower than 3 m according to JMA (Japan Meteorologic Agency) [21] data for Fukue Port and the main tidal constituent is M2. The tide type is mixed and mainly semidiurnal [22].

Two areas were selected for the field measurement campaign in this study. The first one is the Tanoura Strait, 


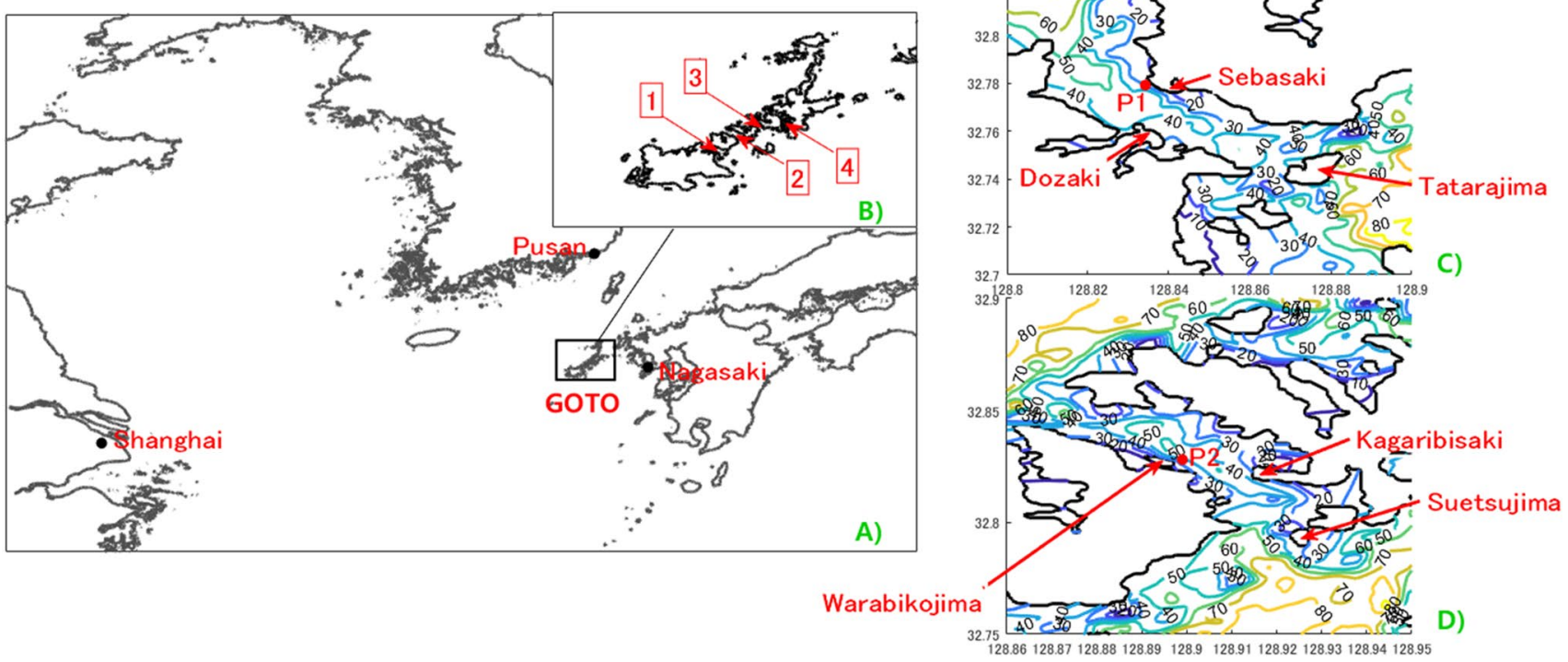

Fig. 1 a Location of Goto Islands; b Goto Islands: (1) Tanoura Strait. (2) Naru Strait. (3) Takigahara Strait. (4) Wakamatsu Strait; c bathymetry map and measurement point location in Tanoura Strait; $\mathbf{d}$ bathymetry map and measurement point location in Naru Strait (right)

between Fukue Island and Hisaka Island, the westernmost channel of the archipelago. Its dimensions are approximately $6 \mathrm{~km}$ length and $2 \mathrm{~km}$ width, and the bottom is chiefly rocky. The main flow direction is SE-NW during flood tide and vice versa for ebb tide, with minor variations due to geomorphologic conditions. The flow is strongly affected by Tatarajima Island in the southern mouth of the channel, and Sebazaki cape is also important in this study due to the closeness to the measuring device installation point (P1). The measuring point in the Tanoura Strait is located at a distance of around $200 \mathrm{~m}$ from the nearest point of Hisaka Island's coastline (Fig. 1). The mean depth at $\mathrm{P} 1$ is $26.1 \mathrm{~m}$.

The second selected area is the Naru Strait, between Hisaka Island and Naru Island. Tidal current characteristics of this area are influenced by Kagaribisaki cape and Suetsujima Island (marked in Fig. 1) in the central area and the south mouth of the strait, respectively; the width at these points is slightly greater than $1 \mathrm{~km}$. The total length of the channel is roughly $7 \mathrm{~km}$ and the mean width varies between 1.5 and $2 \mathrm{~km}$, with the exception of the two points mentioned above. The main axis direction of the Naru channel is SE-NW and the bottom is mainly rocky. The mean depth at the measuring point in the Naru Strait (P2), nearly $300 \mathrm{~m}$ east of Warabikojima Island (see Fig. 1), is $24.6 \mathrm{~m}$.

The bathymetry maps for both channels were created using $1 \mathrm{~m}$ resolution depth data measured by an SONIC 2024 Broadband Multibeam Echosounder for the two channels, and $500 \mathrm{~m}$ resolution data from the Japan Oceanographic Data Center (JODC) [23] for the approaches.

\section{Data measurement}

The tidal current measurement device used in the present study is the Vector 3D, an ADV developed by Nortek which collects high-resolution velocity, temperature, and pressure data. The internal sampling rate is $250 \mathrm{~Hz}$, with a maximum output rate of $64 \mathrm{~Hz}$. The sampling volume of this device has a diameter of $15 \mathrm{~mm}$ and a height of $5 \mathrm{~mm}$, while its accuracy is $0.5 \%$ of the measured value $\pm 1 \mathrm{~mm} / \mathrm{s}$. Flow direction is measured by a compass with a $2^{\circ}$ accuracy and a $0.1^{\circ}$ resolution. Two ADVs were located simultaneously at the measuring points marked in the bathymetry maps in Fig. 1 and set at an output sampling rate of $32 \mathrm{~Hz}$ from November 17th at 0:00 h to November 24th at 18:40 h, 2014, covering neap and spring tides as can be observed in Fig. 2. Both devices were set to measure for $180 \mathrm{~s}$ every $10 \mathrm{~min}$, and thus, the number of results for every 3-min data period was 5760. At both locations, the sensor was installed at $3 \mathrm{~m}$ up from the bottom, attached to a stiff installation base, as shown in the diagram in Fig. 3. A summary of the measuring conditions is presented in Table 1.

As an example of the high-frequency velocity fluctuation described in Sect. 1, time series from the period with the greatest 3-min averaged velocity for flood conditions at P2 are shown in Fig. 4. The 30 and $10 \mathrm{~s}$ samples are extracted from the 960 and 320 values surrounding the 3-min middle point. Within a 10 -s period, the $x$-signal fluctuates between -1.832 and $-0.003 \mathrm{~m} / \mathrm{s}$, the $y$-signal from 0.555 to $2.385 \mathrm{~m} / \mathrm{s}$, and the $z$-signal between -0.711 and $0.447 \mathrm{~m} / \mathrm{s}$. 


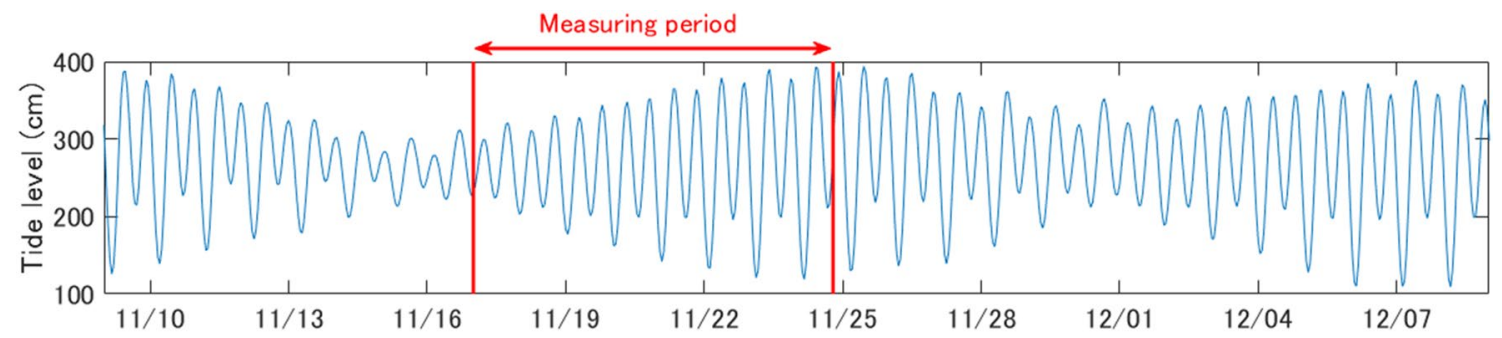

Fig. 2 Tidal level (cm) time series at the Japan Meteorological Agency Station in Fukue Port (Tanoura Strait)

\section{Sea Surface}

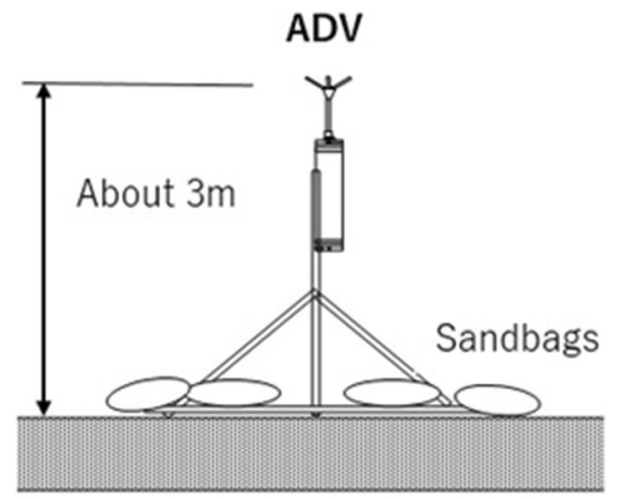

Fig. 3 Schematic of ADV installation

Figure 5 shows hodographs for both locations, based on 3-min averaged data obtained over the 1-week measurement campaign. The flow at $\mathrm{P} 1$ follows the main direction of the channel, from southeast to northwest during the flood tide and vice versa during ebb tide with a small variation between the two directions of the flow due to the presence of the cape some meters east of the measuring point (Fig. 1). The hodograph obtained for $\mathrm{P} 2$ shows similar flow conditions
(SE-NW for flood tide and NW-SE for ebb tide) following the main direction of the channel. The mean velocities during flood tide are more scattered than during ebb tide. In $\mathrm{P} 1$, the maximum velocity values are obtained during ebb tide, marginally surpassing $2 \mathrm{~m} / \mathrm{s}$. In P2, maximum 3-min averaged velocity magnitude was found similar for both flow directions at roughly $1.75 \mathrm{~m} / \mathrm{s}$.

Since both Naru and Tanoura Straits are open to the Pacific Ocean and the Sea of Japan by their southern and northern mouths, respectively, waves could have a significant impact on the velocity fluctuations. For this reason, wave conditions at the area of study were analysed from the data measured by a Nortek AWAC in the Naru Strait (32 49 $34 \mathrm{~N}, 1285447$ E) from October 3rd 2014 for 3 months. Wave measurement was complemented with wind data for the same time period extracted from the JMA station [21] in Fukue Island, located at (32 $4136 \mathrm{~N}, 1284936 \mathrm{E}$ ) at $25.1 \mathrm{~m}$ above sea level (see Fig. 1). Results from this analysis, presented in Appendix I, show no significant effect of waves or wind for the depth at which current velocity data are measured.

\section{Data processing and results}

\subsection{Preliminary analysis}

Preceding the main data analysis, two preliminary steps were necessary to ensure data quality and make further results more comprehensible. The first step was noise elimination. Following the manufacturer's recommendations [24], points for which correlation is under $70 \%$ were discarded. $5.59 \%$ of all points were eliminated for P1 in Tanoura Strait and 1.78\% for P2 in Naru Strait. The resulting signals were despiked
Table 1 Location and measuring setup characteristics at P1 (Tanoura Strait) and P2 (Naru Strait)

\begin{tabular}{lllllllll}
\hline Point & Latitude Longitude & Deployment & Retrieval & $\begin{array}{l}\text { Sampling } \\
\text { frequency } \\
(\mathrm{Hz})\end{array}$ & Depth (m) & $\begin{array}{l}\text { Measuring } \\
\text { time (min) }\end{array}$ & $\begin{array}{l}\text { Standby } \\
\text { time } \\
(\mathrm{min})\end{array}$ \\
\hline P1 & 32.7792 & 128.8342 & $2014 / 11 / 17$ & $2014 / 11 / 24$ & 32 & 26.1 & 3 & 7 \\
P2 & 32.8281 & 128.8990 & $2014 / 11 / 17$ & $2014 / 11 / 24$ & 32 & 24.6 & 3 & 7 \\
\hline
\end{tabular}


Fig. 4 Time fluctuation of $x$ (blue), $y$ (red), and $z$ (black) velocity components for $3 \mathrm{~min}$, 30 , and $10 \mathrm{~s}$ period for the maximum averaged velocity 3-min period during spring flood tide in P2 (Naru Strait)
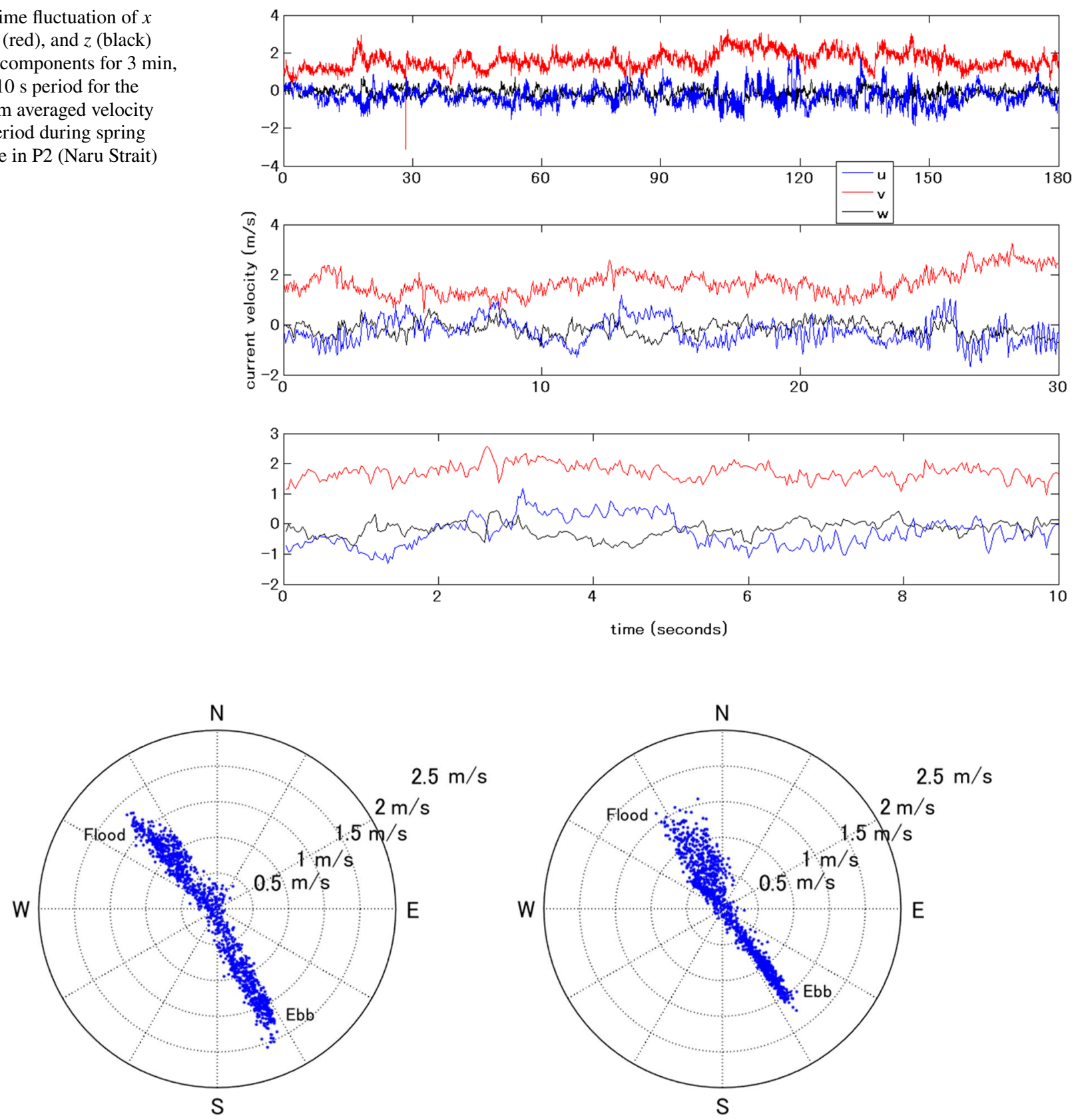

Fig. 5 Hodograph of the mean velocities in P1, Tanoura Strait (left) and in P2, Naru Strait (right). Measured data (blue) and rotated to N-S axis parallel (red)

using a kernel density-based algorithm developed by Islam and Zhu [25] for ADV signals. Removed data were replaced by linearly interpolated values. By this method, $0.55 \%$ of the previously denoised data in $\mathrm{P} 1$ and $1.36 \%$ in $\mathrm{P} 2$ were replaced. A comparison of raw signal and denoised and despiked data for a 3 min period in P1 is presented in Fig. 6 . The second of these steps consists on transforming the original velocity data to a streamwise (s), transverse (t), and vertical (v) coordinate system, by rotating the measured data. The rotation angle is calculated by the least square method using the averaged values of north and east components of velocity for every $3-\min$ period. The resulting angles for $\mathrm{P} 1$ are $42.49^{\circ}$ for flood tide and $27.43^{\circ}$ for ebb tide. In P2, they are $25.10^{\circ}$ and $36.30^{\circ}$. A distribution parallel to the north-south axis is thus obtained. Once this preliminary process was fulfilled, the remaining analysis was focused on evaluating and quantifying the turbulence characteristics at the two studied points. As we are not concerned with the current direction, in the following sections, the streamwise component during ebb tide is presented as an absolute value for convenience. 

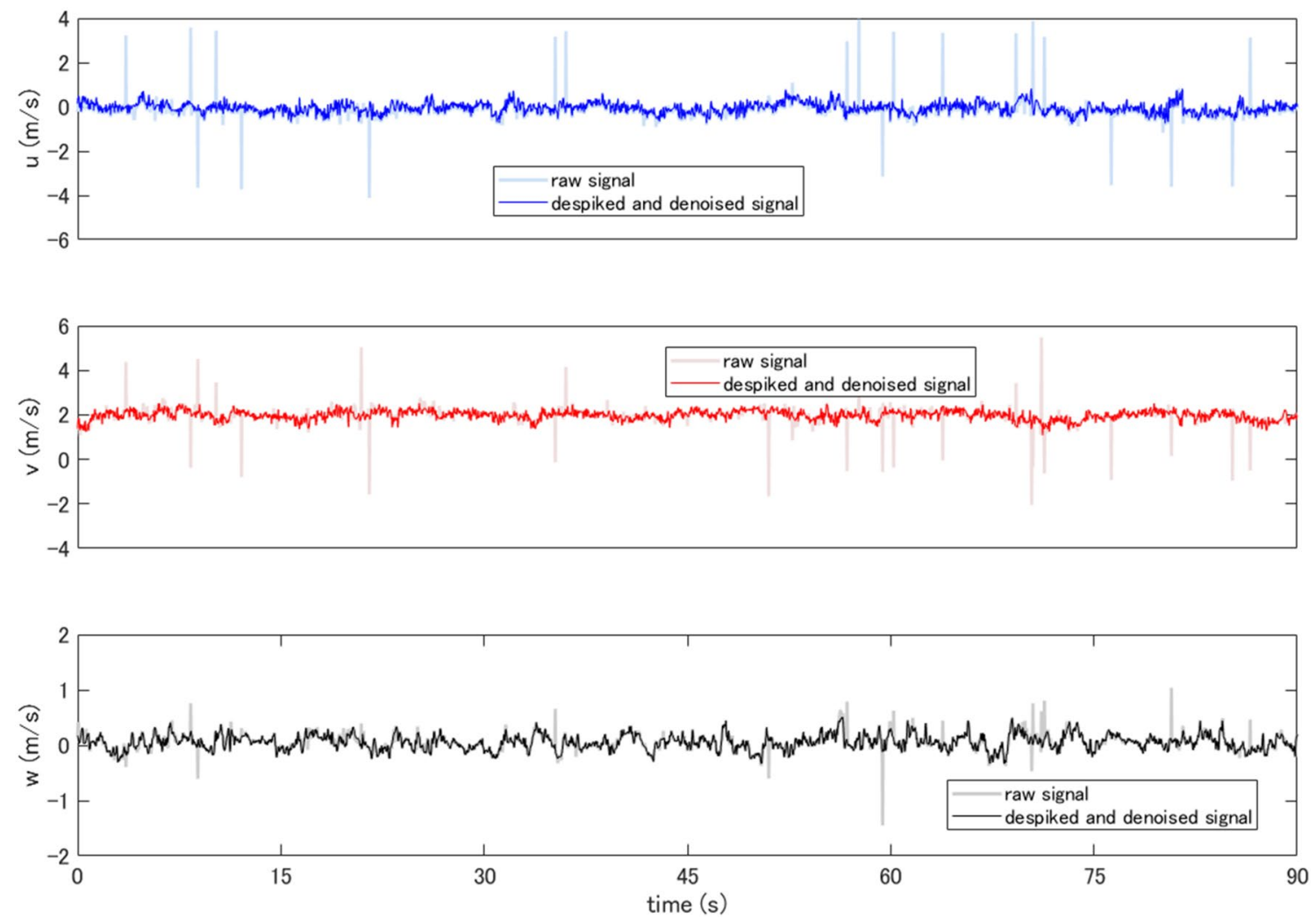

Fig. 6 Raw (weak colour line) and denoised and despiked (strong colour line) data time series of streamwise, transverse, and vertical velocities for the 3-min period with maximum averaged velocity during spring flood tide in P1 (Tanoura Strait)

\subsection{Histograms}

As mentioned in Sect. 1, one of the problems caused by turbulence for tidal current energy converters is the response to extreme velocity values. For this reason, a description of turbulence conditions in terms of velocity magnitude is necessary. Results obtained for the three velocity components in $\mathrm{P} 1$ and $\mathrm{P} 2$ are presented in Figs. 7 and 8, which represent the conditions for the strongest currents during spring ebb tide and spring flood tide, in red and blue, respectively. In all the figures presented, a normal distribution curve is included. The 3-min data representing maximum spring ebb tide in P1 were collected on November 23rd at 00:30 h. For flood tide, 3 min starting on November 23rd at 07:10 h are used. For P2, flood representative data are picked from the same time period as for $\mathrm{P} 2$, while, for ebb tide, the 3 -min period selected occurs from November 24th at 00:50 h.

In P1, there are no notable differences between ebb and flood. Peak values are approximately $150 \%$ of the $3-\mathrm{min}$ average along the streamwise axis, a mean value slightly lower than $0 \mathrm{~m} / \mathrm{s}$, and statistical range roughly $1.5 \mathrm{~m} / \mathrm{s}$ for the transverse component and a range of near $0.9 \mathrm{~m} / \mathrm{s}$ for the vertical component of velocity. In the case of P2, there is an evident difference depending on flow direction. In addition to the mean speed contrast between both cases, the range is shown to be substantially bigger during flood tide for the three components of velocity (approximately twice the values for ebb tide). Thus, it can be expected that the turbulence is significantly stronger during flood tide. Concerning velocity magnitude, peak values close to $2.8 \mathrm{~m} / \mathrm{s}$ for streamwise velocity are observed during flood tide.

Averaged velocity and standard deviation for the two locations and the two flow directions are detailed in Table 2. This information underlines the conclusions extracted from Figs. 7 and 8. A maximum current speed slightly lower than $2 \mathrm{~m} / \mathrm{s}$ appears in $\mathrm{P} 1$; and, in both cases, ebb tide mean velocity is higher than for flood conditions. The difference in the statistical range between the two tide directions in P2 in Naru Strait (presented in the histograms in Fig. 8) is also reflected in the standard deviation values for the three velocity components, which are nearly twice as high during flood tide.

\subsection{Integral scales of turbulence}

The influence of length scales on the behaviour of tidal current turbines has been proved in the previous studies (see Sect. 1). Integral length scale can be calculated from 

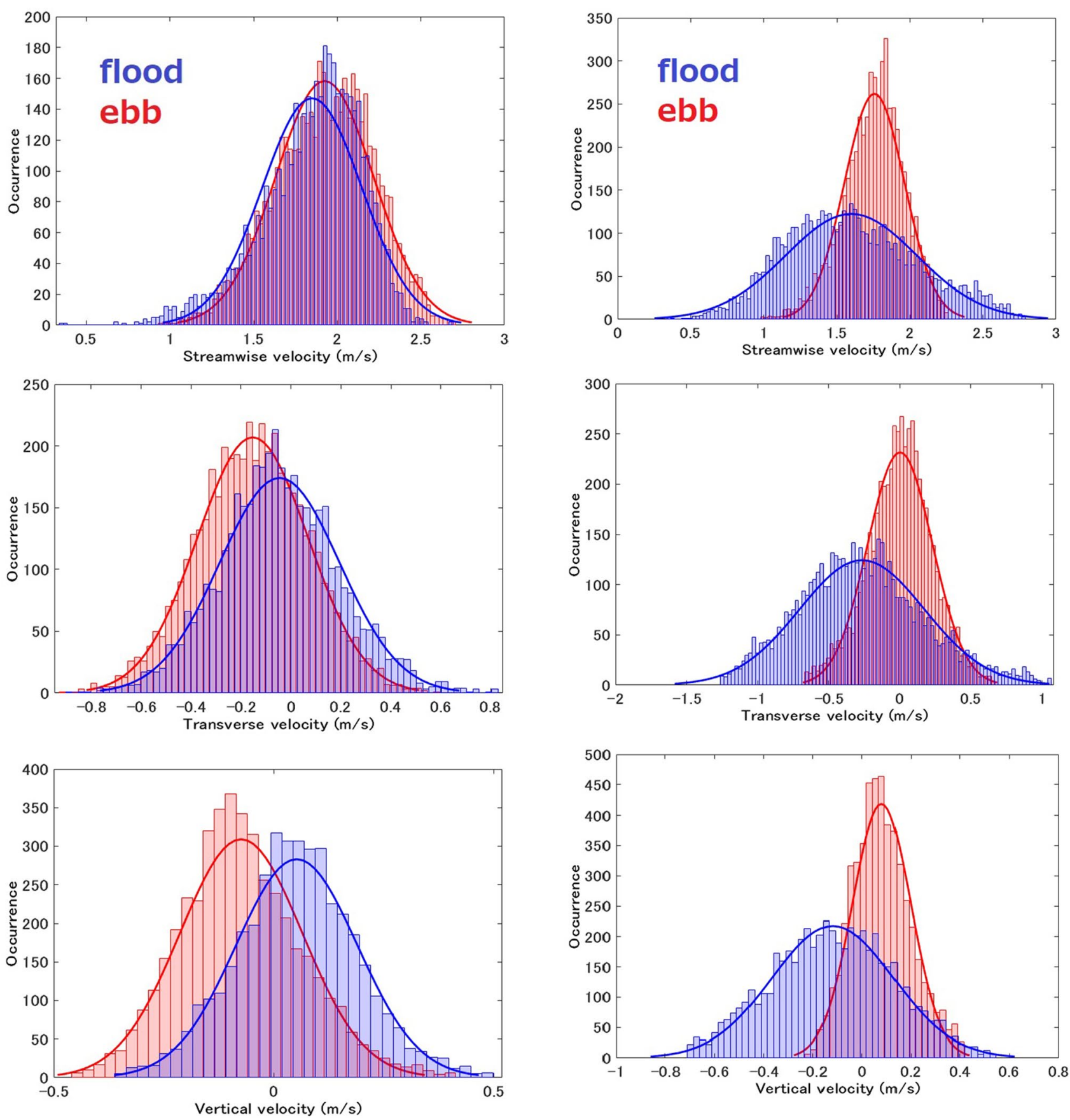

Fig. 7 Histograms of streamwise, transverse, and vertical components of velocity for the maximum averaged velocity 3 -min period during ebb (red) and flood (blue) tide in P1 (Tanoura Strait)

integral time scale $\left(\operatorname{ITS}_{i}\right)$, a parameter defined in Eq. 1 which measures the correlation between observations of a time series that are separated by $\tau$ time units $\left(Y_{t}, Y_{t+\tau}\right)$. Integral time scale was calculated for the three velocity components on the basis of the autocorrelation function $R_{i i}[11]$ :

$$
\begin{aligned}
\mathrm{ITS}_{i} & =\int_{\tau=0}^{\tau\left(R_{i i}(\tau)=0\right)} R_{i i}(\tau) \mathrm{d} \tau, \\
R_{i i}(\tau) & =\frac{\sum_{t=1}^{T-\tau}\left(Y_{t}-\bar{Y}\right)\left(Y_{t+\tau}-\bar{Y}\right)}{\sum_{t-1}^{T}\left(Y_{t}-\bar{Y}\right)^{2}} .
\end{aligned}
$$


Table 2 Mean and standard deviation values for streamwise, transverse, and vertical components of velocity for the maximum velocity 3-min period during ebb and flood tide in P1 and P2

\begin{tabular}{lcllll}
\hline & \multicolumn{2}{l}{ Flood } & & & Ebb \\
\cline { 2 - 3 } \cline { 5 - 6 } & Mean $(\mathrm{m} / \mathrm{s})$ & $\begin{array}{l}\text { Std. dev. } \\
(\mathrm{m} / \mathrm{s})\end{array}$ & & Mean $(\mathrm{m} / \mathrm{s})$ & $\begin{array}{l}\text { Std. dev. } \\
(\mathrm{m} / \mathrm{s})\end{array}$ \\
\hline P1 & & & & \\
Streamwise & 1.849 & 0.298 & & 1.924 & 0.294 \\
Transverse & -0.046 & 0.240 & & -0.153 & 0.221 \\
Vertical & 0.052 & 0.138 & & -0.074 & 0.139 \\
P2 & & & & \\
Streamwise & 1.599 & 0.449 & & 1.757 & 0.206 \\
Transverse & -0.266 & 0.439 & & 0.002 & 0.228 \\
Vertical & -0.119 & 0.247 & & 0.080 & 0.119 \\
\hline
\end{tabular}

Using only the 3-min data groups for which averaged velocity is higher than $0.7 \mathrm{~m} / \mathrm{s}$, a common cut-in speed value within the most advanced tidal current energy turbine designs [18], and separating the results depending on location and flow direction, the averaged time scales, and standard deviations are obtained. Results, presented in Table 3, show similar conditions for all the cases, with mean streamwise time scales between 4 and $5 \mathrm{~s}$, and lower values for transverse and vertical component.

From the integral time scale and the mean streamwise velocity, the integral length scale is calculated by Taylor's turbulence hypothesis [26].

$L_{i}=U T_{i}$,

where $U$ is the streamwise mean velocity.

Time fluctuation for a 66-h period of integral length scale for the two studied locations is presented in Fig. 9. This short interval, instead of the whole measuring period, is used to make the contrast between different tide conditions more perceptible. For time scales, in these graphics, a difference between the three velocity components is clearly notable, with higher values for the streamwise component and minor
Table 3 Averaged and standard deviation $(\mathrm{AVG} \pm \mathrm{STD})$ of integral time scales (s) for streamwise, transverse, and vertical components

\begin{tabular}{llllllll}
\hline Location and tide & $\mathrm{P} 1$ & & & & & & \\
& Streamwise & Transverse & Vertical & & Streamwise & Transverse & Vertical \\
\hline Flood & $4.77 \pm 3.01$ & $1.64 \pm 1.85$ & $1.11 \pm 0.75$ & & $4.82 \pm 3.11$ & $1.52 \pm 1.13$ & $1.29 \pm 0.76$ \\
Ebb & $4.34 \pm 2.79$ & $1.27 \pm 1.29$ & $1.03 \pm 0.65$ & & $4.07 \pm 2.84$ & $1.28 \pm 1.22$ & $0.80 \pm 0.39$ \\
\hline
\end{tabular}

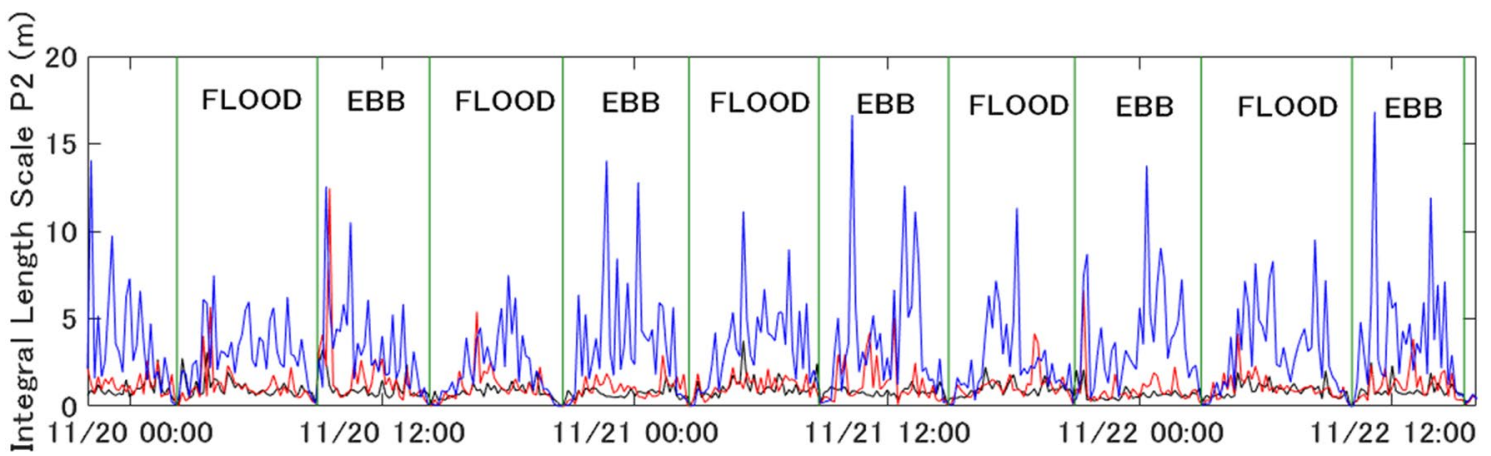

Fig. 9 Time variation of integral length scale for the streamwise (blue), transverse (red), and vertical (black) components at P1 (top) and P2 (bottom) 
Table 4 Averaged and standard deviation $(A V G \pm S T D)$ of integral length scales $(\mathrm{m})$ for streamwise, transverse, and vertical components

\begin{tabular}{|c|c|c|c|c|c|c|}
\hline \multirow[t]{2}{*}{ Location and tide } & \multicolumn{3}{|l|}{ P1 } & \multicolumn{3}{|l|}{$\mathrm{P} 2$} \\
\hline & Streamwise & Transverse & Vertical & Streamwise & Transverse & Vertical \\
\hline Flood & $5.29 \pm 3.52$ & $1.75 \pm 1.80$ & $1.15 \pm 0.64$ & $4.45 \pm 2.87$ & $1.36 \pm 0.80$ & $1.19 \pm 0.62$ \\
\hline Ebb & $5.17 \pm 3.22$ & $1.46 \pm 1.21$ & $1.17 \pm 0.56$ & $4.40 \pm 3.21$ & $1.37 \pm 1.28$ & $0.84 \pm 0.34$ \\
\hline
\end{tabular}

importance of the other two components. Lower results are observed for slack conditions in the three directions.

Averaged integral length scales are presented in Table 4. Slightly higher length scales were found in $\mathrm{P} 1 \quad \approx 5.2$ to $\approx 4.4 \mathrm{~m}$ ). Comparing both directions of the flow in $\mathrm{P} 2$, the different conditions observed in the histograms presented in Sect. 4.1 do not seem to have a notable influence in the vortex dimension.

\subsection{Turbulence intensity}

As presented in Sect. 1, turbulence intensity is one of the most important parameters used to quantify the magnitude of turbulent fluctuations affecting the tidal current converters due to its effect on the generated wakes, turbine power, and thrust coefficients or structure fatigue. In the previous similar works, as well as for laboratory scale turbine test studies, turbulence intensity has been calculated in two different forms: first, as the ratio of the standard deviation of velocity to the mean velocity (Eq. 4) [8, 12]; this formula is also common to equivalent wind studies [27]; Second, as the ratio of the standard deviation of the streamwise component of velocity to the mean streamwise component of velocity (streamwise turbulence intensity) [9]. In this case, due to the apparent importance of transverse component fluctuations, especially in the case of Naru Strait during flood tide, the first option is used:

$\mathrm{TI}=\frac{\sigma_{V}}{V}$.

A representation of the time fluctuation of turbulence intensity for $\mathrm{P} 1$ and $\mathrm{P} 2$ for the same 66-h period presented in Fig. 9 is shown in Fig. 10. In both locations, turbulence intensity values range between 0.1 and 0.3 , except for tidal current slack conditions, when very high turbulence intensity is obtained due to the low values in the denominator. This characteristic for low-velocity conditions has been found in other similar works. In this regard, Thomson et al. [12] defined a "slack conditions" range for which flow turbulence nature is of minor importance for tidal current energy exploitation, so that it can be neglected. The upper limit of this range can be set at the cut-in speed of tidal energy converters. Focusing on P2, in Naru Strait, there is a very clear contrast between the two flow directions, with mean values of approximately 0.15 for ebb tide and 0.25 during flood tide, which is also related to the more scattered nature of velocities presented in Fig. 5. Possible reasons for this difference are the nozzle effect of the Kagaribizaki cape during flood tide (Northeast to Southwest direction) or the impact on the flow of local geomorphologic conditions, with a small
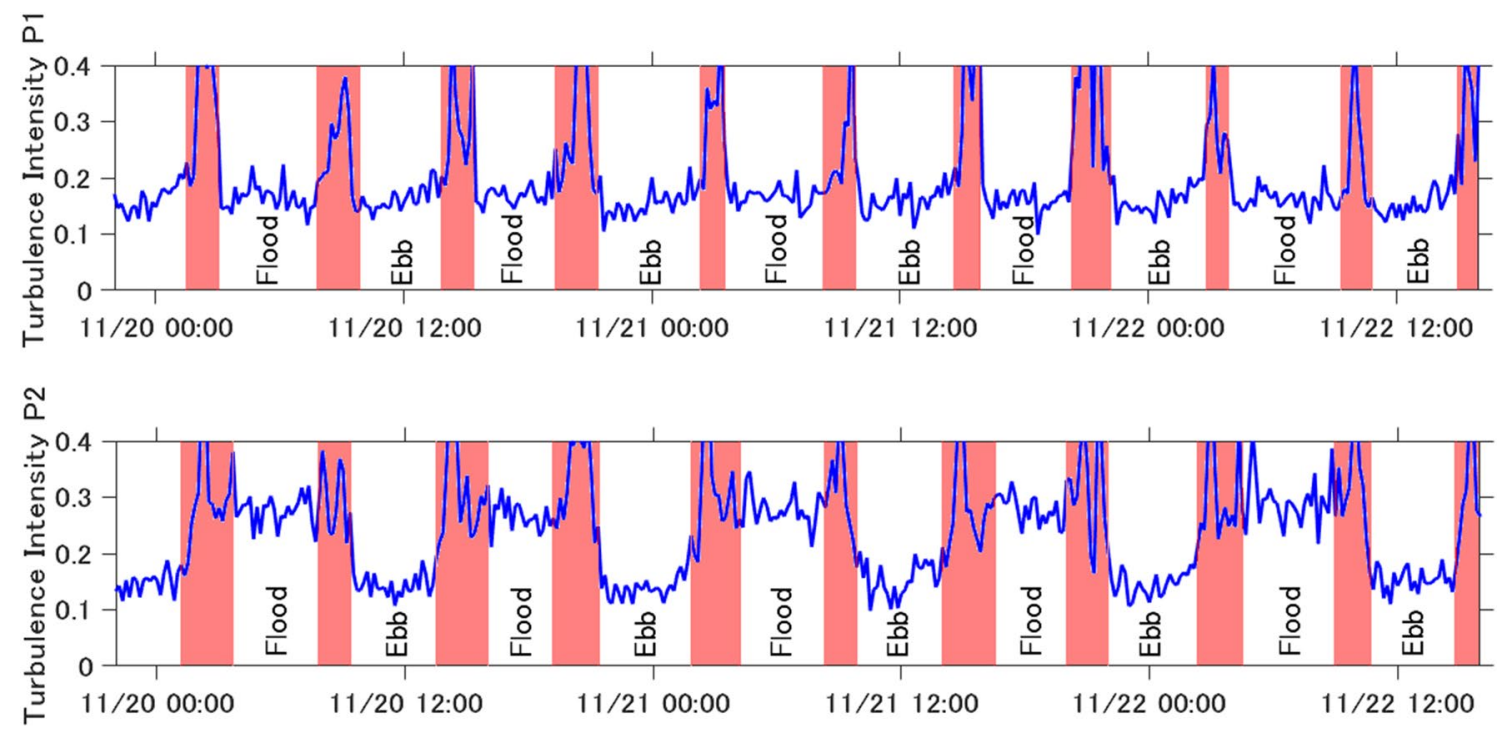

Fig. 10 Time variation of integral length scale for turbulence intensity at P1 (top) and P2 (bottom). Slack water periods are marked in red 


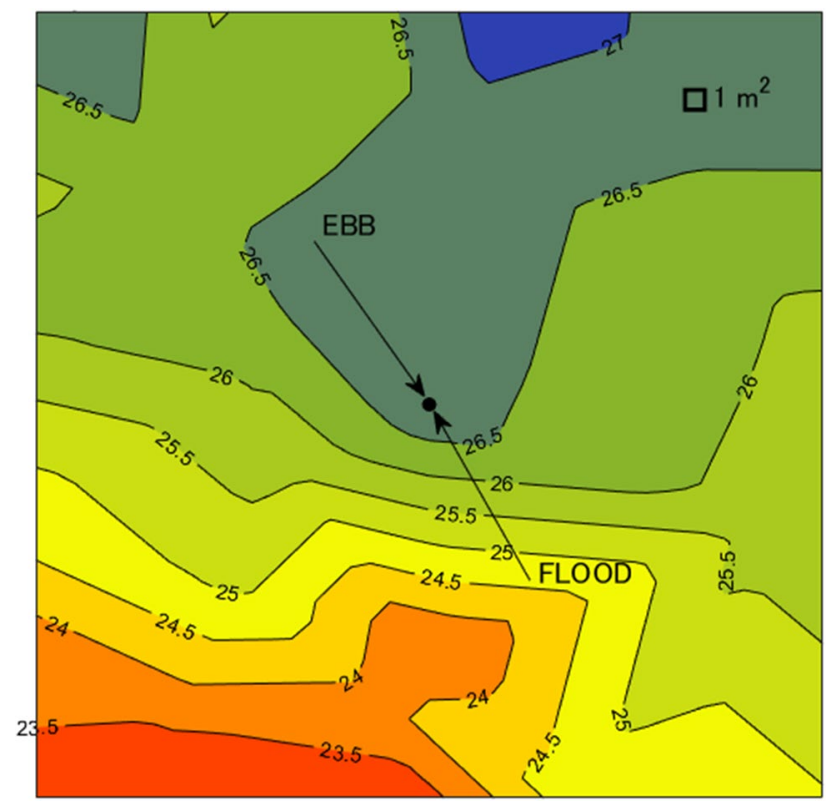

Fig. 11 Bathymetry map of $1 \mathrm{~km}^{2}$ area surrounding P2

underwater hill some meters south of the measuring point, as shown in the map in Fig. 11. This figure includes two 10-m length arrows showing the flow direction towards the measuring point.

\subsection{Discussion}

These results are consistent with those presented in other tidal channel turbulence studies and those used for laboratory turbine tests. As presented in Sect. 1, turbulence intensities between 0.1 and 0.2 at P1 in Tanoura Strait are similar to the results for Sound of Islay in Scotland (0.12-0.13) [11] or Kobe Strait in Japan (0.15-0.17) [13]. As for P2 in the Naru Strait, the notable difference between the two tide directions has been also found in other areas with strong impact of geomorphologic conditions on the flow [12]. In terms of streamwise length scale, both P1 and P2 conditions are close to the measured in Kobe Strait, Goto Islands, for 2-m/s velocities in the ebb direction [13]. Values for flood tide in Kobe Strait $(\approx 12 \mathrm{~m})$, as well as for the point analysed by Milne et al. [11] in the Sound of Islay (11-14 m), are significantly higher, but still comparable.

Measured turbulence conditions were also compared to the theoretical turbulent characteristics by the ratio of standard deviation of transverse and vertical components to that of the streamwise. Based on the experiments at relatively low Reynolds numbers $\left(R e \approx 10^{4}\right)$, Nezu and Nakagawa [28] suggested that $\sigma_{\mathrm{s}}: \sigma_{\mathrm{t}}: \sigma_{\mathrm{v}}=1: 0.71: 0.55$ for a two-dimensional open channel flow. Analysing 3-min data groups for which mean velocity is higher than $0.7 \mathrm{~m} / \mathrm{s}$, ratios obtained for Tanoura and Naru are 1:0.82:0.49 and 1:0.83:0.53, with minor differences between both tide directions. These results agree relatively well with the obtained at the Sound of Islay (1:0.75:0.56) [11], as well as with Nezu and Nakagawa experimental results, with slight variations due to the bathymetry and geomorphologic characteristics of each area and the higher Reynolds numbers of the flow, which are not present in an idealised case.

Another comparison to theoretical results can be made based on the streamwise length scales. Nezu and Nakagawa [28] concluded the following relation for two-dimensional flows in the lower half of the water column:

$L_{\mathrm{s}} \approx \sqrt{z h}$,

where $z$ is the distance from the sea bottom at which data are measured and $h$ the channel depth. According to this relation and the depth and distance to bottom presented in Sect. 2, streamwise length scales for P1 and P2 would be $8.85 \mathrm{~m}$ and $8.59 \mathrm{~m}$. Although these values are higher than the mean length scales in Tanoura Strait and Naru Strait, these results agree moderately well with the data measured, being the theoretical value near the margin of error presented in Table 4. As for the standard deviation ratios, this gap between theoretical and measured values might be due to the geomorphologic conditions of the channel and the higher Reynolds number. This condition is consistent with the other similar studies [11], with length scales for strong tidal current channels slightly lower than the expected from Nezu and Nakagawa theoretical approximation.

Obviating the difference due to the non-idealised conditions at P1 and P2, a relatively good agreement between theoretical and measured conditions for integral length scales and turbulence intensity (based on the standard deviation ratios) was found. Thus, conclusions extracted from the results presented here can also be applied to the other similar tidal turbulent flows.

\subsection{Peak velocity estimation}

Extreme velocities are parameterised by a peak-to-averaged ratio (PAR), defined as the maximum peak value divided by the mean velocity, calculated for every 3-min group of data. This ratio allows the comparison of results for different tide conditions, as well as a direct matching with turbulence intensity due to unit consistency. Three-dimensional figures representing PAR, turbulence intensity, and averaged velocity for every 3-min period are presented in Fig. 12. In the 4 represented cases, the trends are similar. Convex curves appear in the $X Z$ and $X Y$ planes, with higher PAR and TI values for slack conditions (due to the low values in the denominator), strongly decreasing until $\bar{V} \approx 0.5 \mathrm{~m} / \mathrm{s}$, and a very slight descent from $\bar{V} \approx 0.5 \mathrm{~m} / \mathrm{s}$ to the maximum averaged velocities. In the $Y Z$ plane, a linear trend between PAR and TI was found. For ebb 
Fig. 12 Turbulence intensity, mean velocity, and PAR relation in ebb (red) and flood (blue) for P1 (top) and P2 (bottom) tide
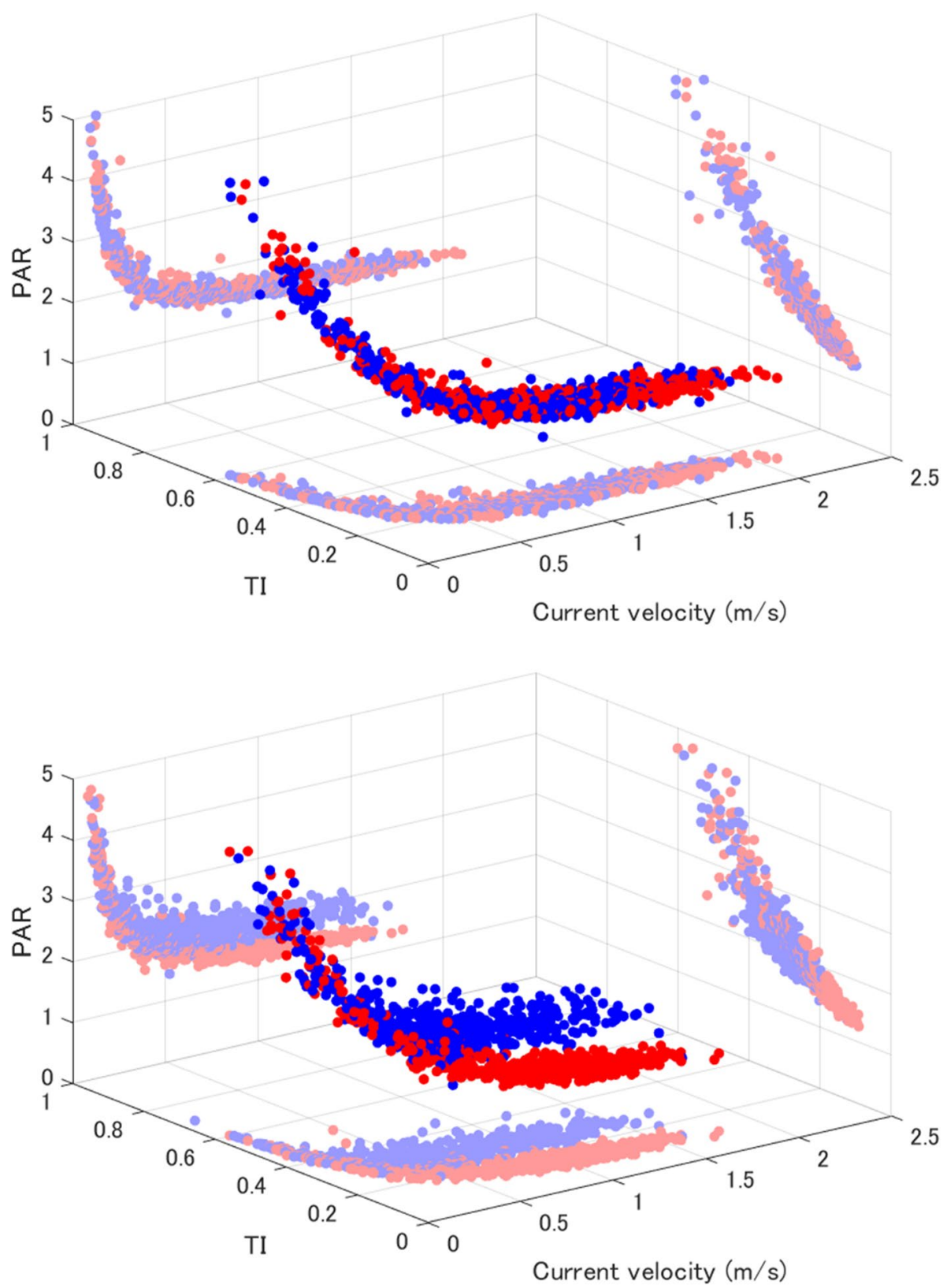

tide (right), results are similar at both measuring points. PAR smoothly decreases from 1.5 to 1.4 for mean current velocities approximately $0.5-2 \mathrm{~m} / \mathrm{s}$, respectively. For flood tide, the difference between P1 and P2 is evident. For 3-min averaged current velocities close to $1.5 \mathrm{~m} / \mathrm{s}$, PAR reaches values close to 2 in Naru Strait and 1.5 in Tanoura Strait.

Focusing in the $Y Z$ plane, at both points, a linear relationship PAR $=a \times \mathrm{TI}+b$ between both parameters is observed. It is also noteworthy that, in the graphic representing P1 conditions, two clear dot areas appear due to the different turbulence conditions for flood and ebb tides, and both of them follow the same trend. Thus, it can be expected that similar PAR-TI relations occur under various flow conditions. Theoretically, assuming that for a zero-turbulence flow velocity fluctuation will be nil, it can be concluded that $b=1$. Thus, the resulting approach is defined as follows:

$\mathrm{PAR}=a \times \mathrm{TI}+1$.

Averaged results for $a$ and PAR for the four tide conditions represented in Fig. 14 are shown in Fig. 13. In this case, only 3-min data group for which averaged velocity is higher than $0.7 \mathrm{~m} / \mathrm{s}$ were used. Despite the already mentioned gap between averaged PAR obtained for Naru flood tide and for the other three tide conditions, no significant variations in $\bar{a}$ value are found between the very different flow turbulence characteristics, which confirm the consistency of this PAR-TI correlation expected from the $Y Z$ plane results in Fig. 12. Device experimental error means less than 
Fig. 13 Averaged PAR and a for Tanoura flood tide, Tanoura ebb tide, Naru flood tide, and Naru ebb tide

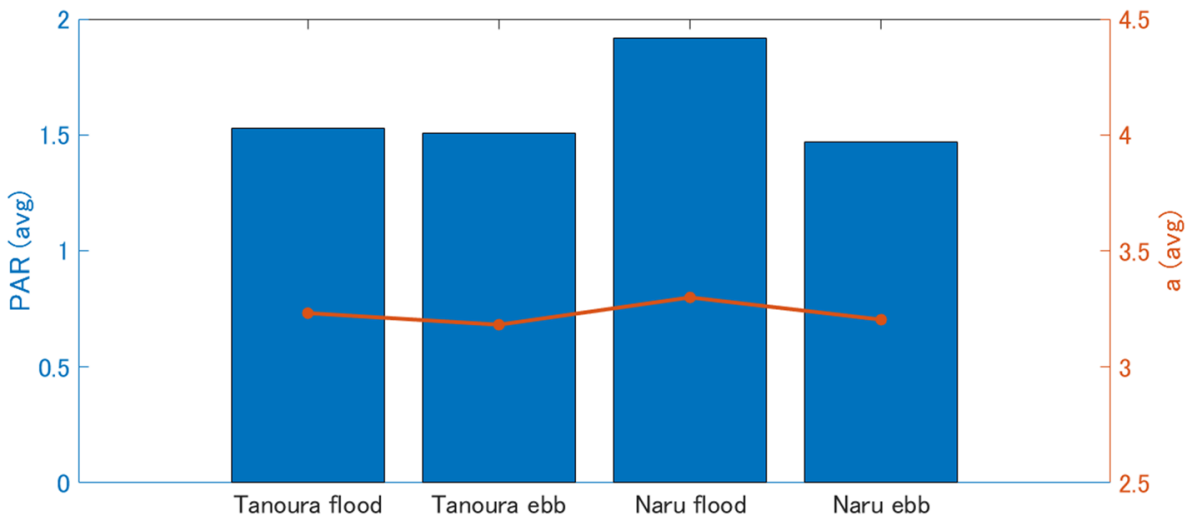

$2 \%$ in the $a$ parameter calculation and less than $0.7 \%$ in the PAR, so it is not considered in this figure.

The averaged $a$ values, obtained from 3-min data groups for which mean velocity is higher than $0.7 \mathrm{~m} / \mathrm{s}$ and presented in Fig. 13, are used to reach a global approach for the estimation of peak velocities. Results are presented for the four analysed tide conditions in Table 5, including also the margin of error calculated by adding the ADV experimental error to the standard deviation. Furthermore, four averaged linear approaches are proposed for the prediction of peak velocities, one for each tide condition (both measuring points, both flow directions). These approaches are calculated as the mean value of the other three $\bar{a}$ parameters, in such a way that the prediction equation is not contaminated with the own peak velocities to be predicted. Thus, the " $a$ " parameter used for the estimation of extreme velocities in P1 during flood tide is calculated as the mean of the three " $a$ " values for P1 during ebb tide, P2 during flood tide, and P2 during ebb tide.
These approaches provide very good results in peak velocity estimations for each of the four cases (ebb and flood tide in $\mathrm{P} 1$ and $\mathrm{P} 2$ ), represented graphically in Fig. 14. Considering only experimental error, not standard deviation, an averaged absolute error slightly lower than $0.09 \mathrm{~m} / \mathrm{s}$ was obtained for flood tide in P2. For the other three tides analysed, this value was between 0.04 and $0.05 \mathrm{~m} / \mathrm{s}$. In terms of averaged relative error, this means $4.41 \%$ for the first case and lower than $3 \%$ for the other three.

The validity of this linear approach is more clearly proved with the prediction levels presented in Table 6. Even for the critical case of flood tide in P2, when the stronger turbulence conditions lead to higher errors, the linear approach can predict more than $80 \%$ of measured data within $0.15 \mathrm{~m} / \mathrm{s}$ or $10 \%$ margin of error. Increasing this margin to $0.2 \mathrm{~m} / \mathrm{s}$ or $20 \%$, the percentage is higher than $90 \%$. Regarding the other tide conditions studied in
Table 5 Averaged and standard deviation values for " $a$ " for different velocity ranges and flow directions in $\mathrm{P} 1$ and $\mathrm{P} 2$

\begin{tabular}{lllll}
\hline Location & Tide direction & Experimental error & $\bar{a}$ & $\sigma_{a}$ \\
\hline P1 (Tanoura) & Flood & Positive & 3.2862 & 0.4105 \\
& & No error & 3.2325 & 0.4067 \\
& \multirow{2}{*}{ Ebb } & Negative & 3.1788 & 0.4030 \\
& & Positive & 3.2368 & 0.3786 \\
& & No error & 3.1825 & 0.3757 \\
P2 (Naru) & Flood & Negative & 3.1283 & 0.3729 \\
& & Positive & 3.3398 & 0.4327 \\
& & No error & 3.3003 & 0.4303 \\
& Ebb & Negative & 3.2607 & 0.4279 \\
& & Positive & 3.2629 & 0.4197 \\
P1 ebb + P2 flood + P2 ebb & & No error & 3.2044 & 0.4160 \\
P1 flood + P2 flood + P2 ebb & & Negative & 3.1460 & 0.4125 \\
P1 flood + P1 ebb + P2 ebb & & & 3.2291 & \\
P1 flood +P1 ebb + P2 flood & & & 3.2457 & \\
\hline
\end{tabular}



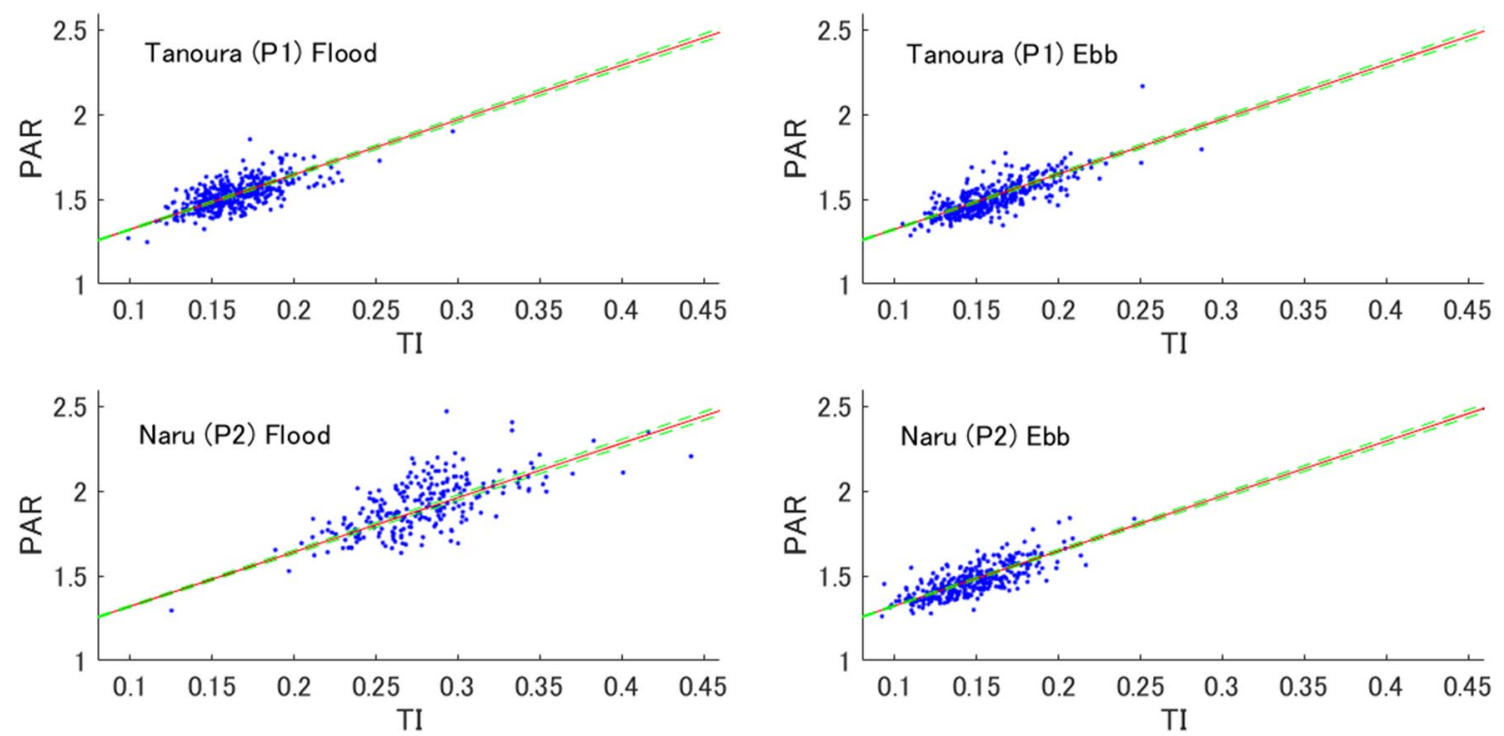

Fig. 14 Peak-to-averaged ratio dependence on turbulence intensity in P1 and P2 for ebb and flood tide and unified equation line (red) with the experimental error representation (dot green)

Table 6 Relative and absolute prediction levels for ebb and flood conditions in P1 and P2 using the unified linear approach

\begin{tabular}{llllllll}
\hline Location and tide & \multicolumn{3}{l}{ Relative prediction level } & & \multicolumn{3}{l}{ Absolute prediction level } \\
\cline { 2 - 3 } & $5 \%$ & $10 \%$ & $15 \%$ & & $0.1 \mathrm{~m} / \mathrm{s}$ & $0.15 \mathrm{~m} / \mathrm{s}$ & $0.2 \mathrm{~m} / \mathrm{s}$ \\
\hline P1 ebb & $85.75 \%$ & $97.93 \%$ & $99.74 \%$ & & $86.01 \%$ & $95.85 \%$ & $98.45 \%$ \\
P1 flood & $79.79 \%$ & $98.69 \%$ & $99.74 \%$ & & $85.04 \%$ & $94.75 \%$ & $98.16 \%$ \\
P2 ebb & $82.14 \%$ & $99.40 \%$ & $100 \%$ & & $90.48 \%$ & $98.21 \%$ & $99.40 \%$ \\
P2 flood & $63.64 \%$ & $93.39 \%$ & $99.17 \%$ & & $66.94 \%$ & $80.58 \%$ & $92.98 \%$ \\
\hline
\end{tabular}

this case, the percentages are over $94 \%$ and $98 \%$ for the above margins of error, respectively.

\section{Conclusions}

Based on $32 \mathrm{~Hz}$ data measured by two ADVs in the Tanoura and Naru Straits of the Goto Islands (Japan), a new method for the estimation of tidal current peak velocities is presented in this study.

Since this method's central premise is that the peak velocities due to high-frequency fluctuation are strongly connected to the turbulence characteristics of the flow, a turbulence analysis is done for both locations. Excluding slack conditions $(\bar{V}<0.7 \mathrm{~m} / \mathrm{s})$, streamwise integral length scales between 3 and $11 \mathrm{~m}$ are found at both locations. Turbulence intensity values close to 0.15 were observed in the Tanoura Strait, while, in the Naru Strait, an important difference between flood and ebb conditions appeared due to the local geomorphologic conditions $(\mathrm{TI} \approx 0.15$ and $\approx 0.25$, respectively).

A method is presented for estimating extreme velocities based on the linear relation between turbulence intensity, which can be estimated by numerical modelling, and a parameter PAR calculated by dividing peak velocity by averaged velocity for a 3-min period $(\mathrm{PAR}=a * \mathrm{TI}+1)$. Despite the very different turbulence conditions, this linear relation shows comparable slopes for both points and tide directions (flood and ebb), which suggests that this connection could be common to other flows with minor wind and wave influence.

Finally, peak velocities are estimated for each analysed condition (P1 flood, P1 ebb, P2 flood, and P2 ebb), being "a" the mean value of the slopes obtained for the other three cases. Results obtained with this approaches show a very high agreement with data measured. For the four studied tide types, this approach can estimate peak velocities within a margin of error of $0.2 \mathrm{~m} / \mathrm{s}$ for more than $92 \%$ of the 3-min period data, and more than $99 \%$ for a margin of error of $15 \%$.

Thus, although the short number and heterogeneity of data does not allow us to state a final mathematical relation between both parameters, the new method presented in this paper may be a starting point for further studies towards being able to predict tidal current extreme velocities from numerical modelling. 
Acknowledgements The authors would like to thank the Ministry of Environment of Japan for permission to publish the data used in this study, which were obtained through the project for Promotion of Realization of Tidal Current Power Generation supported by the ministry in 2014 and 2015. The authors also want to thank Dr. Simon Waldman, for his English language editing.

Open Access This article is distributed under the terms of the Creative Commons Attribution 4.0 International License (http://creativeco mmons.org/licenses/by/4.0/), which permits unrestricted use, distribution, and reproduction in any medium, provided you give appropriate credit to the original author(s) and the source, provide a link to the Creative Commons license, and indicate if changes were made.

\section{References}

1. MacDougall SL (2015) The value of delay in tidal energy development. Energy Policy 87:438-446

2. http://www.emec.org.uk/. Accessed 17 Feb 2013

3. http://openhydro.com/ Accessed 17 Feb 2013

4. TidalEnergyToday (2017) DCNS to retrieve Paimpol-Brehat array for repairs. Accessed Jan 52017

5. Merigaud A, Ringwood JV (2016) Condition-based maintenance methods for marine renewable energy. Renew Sustain Energy Rev 66:53-78

6. Chen L, Lam W-H (2015) A review of survivability and remedial actions of tidal current turbines. Renew Sustain Energy Rev 43:891-900

7. Mycek P, Gaurier B, Germain G, Pinon G, Rivoalen E (2014) Experimental study of the turbulence intensity effects on marine current turbines behaviour. Part I: one single turbine. Renew Energy 66:729-746

8. Blackmore T, Batten WMJ, Bahaj AS (2014) Influence of turbulence on the wake of a marine current turbine simulator. Proc $\mathrm{R}$ Soc A Math Phys Eng Sci 470:20140331

9. Blackmore T, Myers LE, Bahaj AS (2016) Effects of turbulence on tidal turbines: implications to performance, blade loads, and condition monitoring. Int J Mar Energy 14:1-26

10. Pyakurel P, VanZwieten JH, Dhanak M, Xiros NI (2017) Numerical modeling of turbulence and its effect on ocean current turbines. Int J Mar Energy 17:84-97

11. Milne IA, Sharma RN, Flay RGJ, Bickerton S (2013) Characteristics of the turbulence in the flow at a tidal stream power site. Philos Trans R Soc A 371:1-14
12. Thomson J, Polagye B, Durgesh V, Bickerton MC (2012) Measurements of turbulence at two tidal energy sites in Puget Sound, WA. IEEE J Ocean Eng 37(3):363-374

13. Garcia Novo P, Kyozuka Y (2017) Field measurement and numerical study of tidal current turbulence intensity in the Kobe Strait in Goto Islands, Nagasaki Prefecture. J Mar Sci Technol 22:335-350. https://doi.org/10.1007/s00773-016-0414-x

14. Polagye B, Epler J, Thomson J (2010) Limits to the predictability of tidal current energy. In: OCEANS 2010, IEEE. pp 1-9

15. News CBC (2011) Failed tidal turbine explained at symposium. Accessed 08 Jul 2011

16. Harding S, Thomnson J, Polagye B, Richmond M, Durgesh V, Bryden I (2011) Extreme value analysis of tidal stream velocity perturbations. In: Proceedings of the 9th European wave and tidal energy conference, Southampton, UK,

17. Togneri M, Lewis M, Neill SP, Masters I (2017) Comparison of ADCP observations and 3D model simulations of turbulence at a tidal energy site. Renew Energy 114:273-282

18. Ramos V, Carballo R, Alvarez M, Sanchez M, Iglesias G (2014) A port towards energy self-sufficiency using tidal stream power. Energy 71:432-444

19. Carballo R, Iglesias G, Castro A (2009) Numerical model evaluation of tidal stream energy resources in the Ria of Muros (NW Spain). Renew Energy 34(6):1517-1724

20. Guerra M, Cienfuegos R, Thomson J, Suarez L (2017) Tidal energy resource characterization in Chacao Channel, Chile. Int J Mar Energy 20:1-16

21. http://www.jma.go.jp/jma/index.html. Accessed 22 Jul 2017

22. Waldman S, Yamaguchi S, O'Hara Murray R, Woolf D (2017) Tidal resource and interactions between multiple channels in the Goto Islands, Japan. Int J Mar Energy 19:332-334

23. http://www.jodc.go.jp/jodcweb/index.html. Accessed 22 Jul 2017

24. Rusello PJ (2009) A practical primer for pulse coherent instruments. In: Nortek technical note TN-027. NortekUSA, USA. http://www.nortekusa.com/lib/technical-notes/tn-027-pulse-coher ent-primer

25. Islam Z (2013) A kernel density based algorithm to despike ADV data. J Hydraul Eng 139(7):785-793

26. Taylor GI (1938) The spectrum of turbulence. Proc R Soc Lond Ser A Math Phys Sci 164:476-490

27. Göçmen T, Giebel G (2016) Estimation of turbulence intensity using rotor effective wind speed in Lillgrund and Horns Rev-I offshore wind farms. Renew Energy 99:524-532

28. Nezu I, Nakagawa H (1993) Turbulence in open-channel flows. A. A. Balkema, Rotterdam 